\title{
Pre-opsonisation of Escherichia coli induces resistance to neutrophil killing in serum and urine: relationship to growth phase
}

\author{
R. A. GARGAN, W. BRUMFITT and J. M. T. HAMILTON-MILLER
}

Department of Medical Microbiology, The Royal Free Hospital and School of Medicine, Pond Street, Hampstead, London NW3 20G

\begin{abstract}
Summary. Tests of phagocytosis and killing by polymorphonuclear neutrophil leucocytes (PMNL) are usually done with pre-opsonised organisms. Phagocytosis of 11 strains of Escherichia coli, pre-opsonised, and in the stationary phase, resulted in the killing of only one strain although all the organisms were phagocytosed. However, when the same strains were added unopsonised to a PMNL-serum mixture, eight were killed after phagocytosis. With two of these strains, the amount of killing was inversely proportional to the time of preopsonisation. E. coli incubated for $30 \mathrm{~min}$ in dilute peptone water in Hanks's Balanced Salts Solution before phagocytosis also became resistant to killing; bacterial division did not occur during this period. Experiments with bacteria in urine confirmed these findings and showed that $E$. coli exposed to serum or urine before phagocytosis became resistant to killing by PMNL. E. coli rapidly changes its sensitivity to phagolysosome killing during transition from stationary to lag phase in a nutrient medium. This resistance is retained through the exponential phase but is lost during the stationary phase. The killing of Pseudomonas, Enterobacter, and Acinetobacter by PMNL was unaffected by varying the method of opsonisation or the phase of growth. If this phenomenon occurs in vivo it may affect the outcome of infections caused by strains of $E$. coli that survive killing by PMNL.
\end{abstract}

\section{Introduction}

Opsonisation with serum is generally regarded as a pre-requisite for optimal phagocytosis and killing of bacteria by polymorphonuclear neutrophil leucocytes (PMNL). Bacteria can be opsonised either before they are added to the PMNL, here termed "pre-opsonisation", or by adding organisms directly to a mixture of PMNL and serum. The former method allows maximum phagocytosis after 3-5 min, whereas in the latter this is achieved after $10-15 \mathrm{~min} .{ }^{1}$ This may explain why the majority of experimental work reported in this field has been done with pre-opsonised bacteria.

During an investigation of the ability of human PMNL to kill serum-resistant Escherichia coli it was found that the method of opsonisation was a crucial determinant of killing. We examined the relationship between the growth phase of bacteria and killing by PMNL in Hanks's Balanced Salts Solution (HBSS) and in human urine.

\section{Materials and methods}

\section{Isolation of $P M N L$}

Samples $(4 \mathrm{ml})$ of venous blood were taken from healthy donors and anticoagulated with potassium

Received 27 June 1990; revised version accepted 15 Oct. 1990.
EDTA. PMNL were isolated by low speed differential centrifugation in $\mathrm{HBSS}$ without $\mathrm{Ca}^{2+}$ or $\mathrm{Mg}^{2+}$ (Gibco Ltd, Paisley) after lysis of red blood cells in isotonic ammonium chloride. ${ }^{2}$ This method preserves the functional integrity of the cells, including the capacity for intracellular killing. The PMNL were resuspended in $2 \mathrm{ml}$ of HBSS at $4^{\circ} \mathrm{C}$. Under these conditions, the PMNL remain in a stable condition until serum is added. For a limited number of experiments, PMNL were separated by dextran sedimentation. ${ }^{3}$ Whole blood $(4 \mathrm{ml})$ was added to $1 \mathrm{ml}$ of dextran (mol. wt 70000 ) $6 \% \mathrm{w} / \mathrm{v}$ in sodium chloride $0.9 \%$ (Travenol Laboratories Ltd) and allowed to stand for $1 \mathrm{~h}$ at room temperature. The leucocyte-rich supernate was centrifuged, the red blood cells were lysed with isotonic ammonium chloride and, after a further centrifugation, the PMNL were resuspended in HBSS at $4^{\circ} \mathrm{C}$.

\section{Bacteria and culture methods}

Eleven serum-resistant strains of $E$. coli were used. Nine isolates, strains 519 (serotype O4), 395, 398 and 401 (O6), 255 and $325(\mathrm{O} 9), 244$ (O18) and 323 and 441 (O18: K5) from urinary tract infections were supplied by Dr A. Roberts, Department of Microbiology, West London Hospital, Hammersmith Road, London W6 7DQ. Strain Bi-8337 (O10: K5: H4), from a wound infection, was obtained from Mrs F. K. Saunders, 
Department of Microbiology, University Road, Leicester LE1 9HN. Strain 227, from a blood culture, was isolated at the Royal Free Hospital, London. Three other serum-resistant strains of gram-negative species were isolated at this hospital: Pseudomonas aeruginosa and Acinetobacter lwoffi from blood cultures and Enterobacter cloacae from a wound.

All bacteria were grown in Brain Heart Infusion Broth (BHI; CM225, Oxoid). Stationary phase organisms were obtained from static 18 -h cultures at $37^{\circ} \mathrm{C}$. Exponential phase bacteria were from a 1 in 10 dilution of 18-h cultures in fresh BHI, shaken in a water bath at $37^{\circ} \mathrm{C}$ for $100 \mathrm{~min}$. Gram-negative rods other than $E$. coli were shaken for $2 \mathrm{~h}$. All bacteria were washed once in HBSS before use.

Peptone Water (Lab M, Bury), containing peptone $10 \mathrm{~g} / \mathrm{L}$ was diluted 1 in 10 in HBSS.

\section{Opsonisation}

Pre-opsonisation. Washed organisms were diluted in HBSS to a final concentration, in human serum $10 \%$ (from the same donor as the PMNL, except where stated) of $10^{7}-3 \times 10^{7}$ organisms $/ \mathrm{ml}$. The mixture was rotated in a water bath at $120 \mathrm{rpm}$ for $30 \mathrm{~min}$ at $37^{\circ} \mathrm{C}$ and $200 \mu \mathrm{l}$ was added to an equal volume of PMNL suspension $\left(4 \times 10^{6} / \mathrm{ml}\right)$, to give a final bacteria: PMNL ratio of approximately $5: 1$. Serum was added to bring the final concentration back to $10 \%$.

Opsonisation in the reaction mixture. A 200- $\mu 1$ sample of the washed and diluted unopsonised organisms was added directly to $200 \mu \mathrm{l}$ of the PMNL suspension together with serum $10 \%$ to give the same ratio of bacteria to PMNL as above.

\section{Phagocytosis and killing}

Immediately after adding opsonised or unopsonised organisms to the PMNL, $20 \mu \mathrm{l}$ of reaction mixture was removed and added to $4.98 \mathrm{ml}$ of distilled water (Travenol) at $\mathrm{pH} 11$ and held for $5 \mathrm{~min}$ at $37^{\circ} \mathrm{C}$. These conditions completely lysed PMNL without harming the bacteria. ${ }^{4}$ The sample was vigorously shaken and a viable count made, with distilled water (pH 5-6) as diluent, on MacConkey Agar (CM7b, Oxoid). The reaction mixture was rotated at $120 \mathrm{rpm}$ in a water bath for $1 \mathrm{~h}$ at $37^{\circ} \mathrm{C}$ and viable counts were again done. Bacterial killing was expressed as the percentage reduction of the initial viable count. Controls containing bacteria and serum $10 \%$, without PMNL, were examined by the same procedure, to eliminate the possibility of extracellular killing by serum, or bactericidal activity of water at $\mathrm{pH} 11$. Slide preparations of all the PMNL-bacteria mixtures after incubation for $1 \mathrm{~h}$ were made with a Cytospin 2 (Shandon Southern Products Ltd, Cheshire). These were stained with Prodiff (Braidwood Labs) and examined to determine the percentage of PMNL that had phagocytosed bacteria and the mean number of bacteria phagocytosed per PMNL.

\section{Preparation and use of urine}

Urine samples from 16 healthy volunteers (eight males and eight females), without antibacterial activity and with bacterial counts of $\leqslant 10^{3}$ organisms $/ \mathrm{ml}$, were pooled. The pool was filtered through a coarse and a fine filter to remove sediment and finally through a $0.22-\mu \mathrm{m}$ membrane filter (Millipore) to remove bacteria. The pooled urine, pH 6.9, osmolality $504 \mathrm{mOsm} / \mathrm{kg}$ and urea concentration $195 \mathrm{~mm} / \mathrm{L}$, was divided into $20-\mathrm{ml}$ volumes and stored at $-36^{\circ} \mathrm{C}$.

PMNL freshly prepared from blood, as above, were centrifuged from $2 \mathrm{ml}$ of HBSS at $160 \mathrm{~g}$ for $5 \mathrm{~min}$ and resuspended in the same volume of pooled sterile urine shortly before the experiment. Bacteria suspended in HBSS were centrifuged and resuspended in urine immediately before the experiment. All opsonisation, phagocytosis and killing experiments were performed as previously described but with urine in place of HBSS.

\section{Detection of fimbriae}

Mannose-sensitive (MS) fimbrial activity of $E$. coli, grown in Nutrient Broth (Oxoid), was detected by inhibition with D-mannose of the haemagglutination of $3 \%$ horse red blood cells. ${ }^{5}$ Mannose-resistant (MR) haemagglutination by $E$. coli, grown on phosphatebuffered nutrient agar, was demonstrated with group $\mathrm{O}$ human red blood cells $3 \%$ in the presence of $\mathrm{D}$ mannose at $4^{\circ} \mathrm{C}$. E. coli controls with MS, MR and without haemagglutinating activity were included. The test organisms were then incubated with serum $10 \%$ in phosphate-buffered saline for $30 \mathrm{~min}$ with rotation at $120 \mathrm{rpm}$ at $37^{\circ} \mathrm{C}$ (i.e., pre-opsonised), washed once and the haemagglutination tests were repeated.

\section{Results}

Effect of method of opsonisation on killing of E. coli by $P M N L$

Only one strain (244) of the $11 E$. coli strains tested was killed by PMNL after pre-opsonisation, despite good phagocytosis of all the strains (average $89 \%$ with a mean uptake of 5.5 organisms/cell). This was confirmed in three separate experiments with PMNL isolated from three individuals with homologous serum (table I). As this resistance to PMNL killing in the majority of $E$. coli strains appeared unusual, the growth conditions of the $E$. coli and the separation technique for the PMNL was varied to attempt to achieve greater killing. When the same 11 strains were tested in their exponential phase, the same results were obtained. PMNL separated by dextran (10 experiments with PMNL from four donors) were similarly unable to kill the $E$. coli strains. With heparin as the anticoagulant instead of EDTA, there was no difference in the results. 
Table I. Effect of opsonisation on killing and phagocytosis of $E$. coli: strains tested fall into three groups, (i) always killed (244), (ii) never killed $(255,325)$, (iii) killing depended on the method of opsonisation (remaining strains)

\begin{tabular}{r|ccccc}
\hline & \multicolumn{2}{|c}{ Percentage killing of } & & \multicolumn{2}{c}{ Percentage phagocytosis of } \\
\cline { 2 - 3 } \cline { 5 - 5 } Strain no. & $\begin{array}{c}\text { pre- } \\
\text { opsonised } \\
\text { bacteria }\end{array}$ & $\begin{array}{c}\text { bacteria } \\
\text { opsonised } \\
\text { in reaction } \\
\text { mixture }\end{array}$ & & $\begin{array}{c}\text { pre- } \\
\text { opsonised } \\
\text { bacteria }\end{array}$ & $\begin{array}{c}\text { bacteria } \\
\text { opsonised } \\
\text { in reaction } \\
\text { mixture }\end{array}$ \\
\hline (i) 244 & $81^{*}(12)$ & $91(8)$ & $87(2)$ & $94(5)$ \\
(ii) 255 & 0 & 0 & $68(7)$ & $53(4)$ \\
325 & 0 & 0 & $66(12)$ & $62(12)$ \\
& & & & \\
(iii) 323 & 0 & $59(18)$ & $99(1)$ & $99(1)$ \\
395 & 0 & $74(17)$ & $96(3)$ & $99(1)$ \\
398 & 0 & $80(8)$ & $99(1)$ & $99(2)$ \\
401 & 0 & $85(3)$ & $97(4)$ & $86(8)$ \\
441 & 0 & $81(9)$ & $92(5)$ & $94(6)$ \\
519 & 0 & $78(8)$ & $92(8)$ & $90(6)$ \\
227 & 0 & $70(11)$ & $97(2)$ & $96(2)$ \\
Bi-8337 & 0 & $82(8)$ & $92(8)$ & $96(3)$ \\
\hline
\end{tabular}

* Results are expressed as the mean (SD) of three experiments on each strain.

However, when these $E$. coli strains were opsonised in the reaction mixture, instead of being pre-opsonised, intracellular killing of a further eight of the strains was achieved (mean kill $76 \%$ SD $12 \cdot 2 \%$, table I). The eleven strains were ingested by an average of $88 \%$ of the PMNL with an mean uptake of 4.9 E. coli/PMNL (table I). These results were confirmed in three experiments each with a different donor of PMNL: homologous serum was used with PMNL from one individual and autologous serum with PMNL from the other two. When PMNL separated by dextran sedimentation were used, similar results were obtained (mean kill $74 \%$ SD $11 \cdot 7 \%, \mathrm{n}=10$ ). A difference in the microscopic appearance of the intracellular $E$. coli under the two conditions of opsonisation was particularly apparent with one strain (Bi-8337) and correlated with these findings (fig. 1). Control experiments showed that killing did not take place in the presence of serum alone and that water at $\mathrm{pH} 11$ was not bactericidal for any of the $E$. coli strains.

\section{Time course of pre-opsonisation}

To ascertain how long the $E$. coli strains could be exposed to serum before they became resistant to intracellular killing, two strains (441 and Bi-8337) were opsonised in serum $10 \%$ in HBSS for between 0 and $30 \mathrm{~min}$ before exposure to PMNL and phagocytosis. Killing of $68 \%$ and $73 \%$ was found without preopsonisation, $58 \%$ and $44 \%$ after pre-opsonisation for $15 \mathrm{~min}$, and no killing after pre-opsonisation for $20 \mathrm{~min}$ (fig. 2).

\section{Effect of nutrients on killing}

Pre-opsonisation in serum exposes the organisms to a nutrient environment which allows them to begin to prepare for multiplication. To establish whether such a nutrient environment could be the cause of the organisms becoming resistant to killing by PMNL, three $E$. coli strains (401, 441 and $\mathrm{Bi}-8337$ ), grown overnight, were incubated in a 1 in 10 dilution of peptone water in HBSS for $30 \mathrm{~min}$, instead of serum $10 \%$, before opsonisation in the PMNL-serum reaction mixture. None of these three $E$. coli strains was killed by the PMNL (table II), despite good phagocytosis. The same $E$. coli strains incubated for $30 \mathrm{~min}$ in HBSS alone, before opsonisation and phagocytosis in the reaction mixture, were killed, as were control organisms opsonised and phagocytosed in the reaction mixture in the presence of a 1 in 10 dilution of peptone water (table II). Viable counts on stationary phase $E$. coli before and after the 30-min incubation showed that bacterial multiplication had not taken place in either HBSS or in a 1 in 10 dilution of peptone water in HBSS.

\section{Effect of growth phase on killing}

Eight strains of $E$. coli, which in their stationary phase became resistant to killing after pre-opsonisation, were grown to the exponential phase and added unopsonised to the PMNL-serum reaction mixture. All were resistant to killing by PMNL (table III, mean phagocytosis $78 \%$, average uptake 2.9 organisms/cell).

Two of the strains (Bi-8337 and 401) were grown in shaken cultures in BHI for $6 \mathrm{~h}$; samples of bacteria were removed at hourly intervals, washed and added unopsonised to the PMNL-serum reaction mixture. Viable counts performed every hour indicated that both organisms had reached their stationary growth phase after $3 \mathrm{~h}$. The short exponential phase was due to a heavy inoculum (see Materials and methods). Strain Bi-8337, which was resistant to killing by PMNL for the first $2 \mathrm{~h}$, became sensitive to killing (mean kill $81 \%$ SD $3 \cdot 2, \mathrm{n}=3$ ) after $3 \mathrm{~h}$. However, strain 401 started to become sensitive to killing only after incubation for $6 \mathrm{~h}$ (mean kill $44 \%, \mathrm{n}=2$ ).

\section{Effect of pre-opsonisation on bacterial growth}

There was no increase in the viable counts of any of the stationary phase $E$. coli after pre-opsonisation for

Table II. Effect of pre-incubation on killing of $E$. coli by PMNL

\begin{tabular}{|c|c|c|c|}
\hline \multirow{3}{*}{$\begin{array}{l}\text { Strain } \\
\text { no. }\end{array}$} & \multicolumn{3}{|c|}{ Percentage killing of $E$. coli } \\
\hline & \multicolumn{2}{|c|}{$\begin{array}{c}\text { after } 30 \text { min pre-incubation } \\
\text { in }\end{array}$} & \multirow{2}{*}{$\begin{array}{l}\text { opsonised in reaction } \\
\text { mixture containing } \\
\text { dilute peptone water }\end{array}$} \\
\hline & HBSS & $\begin{array}{l}\text { HBSS + dilute } \\
\text { peptone water }\end{array}$ & \\
\hline 401 & $83^{*}$ & 0 & 88 \\
\hline 441 & 72 & 0 & 89 \\
\hline Bi-8337 & 79 & 0 & 77 \\
\hline
\end{tabular}

*Results are expressed as the mean of two experiments. 

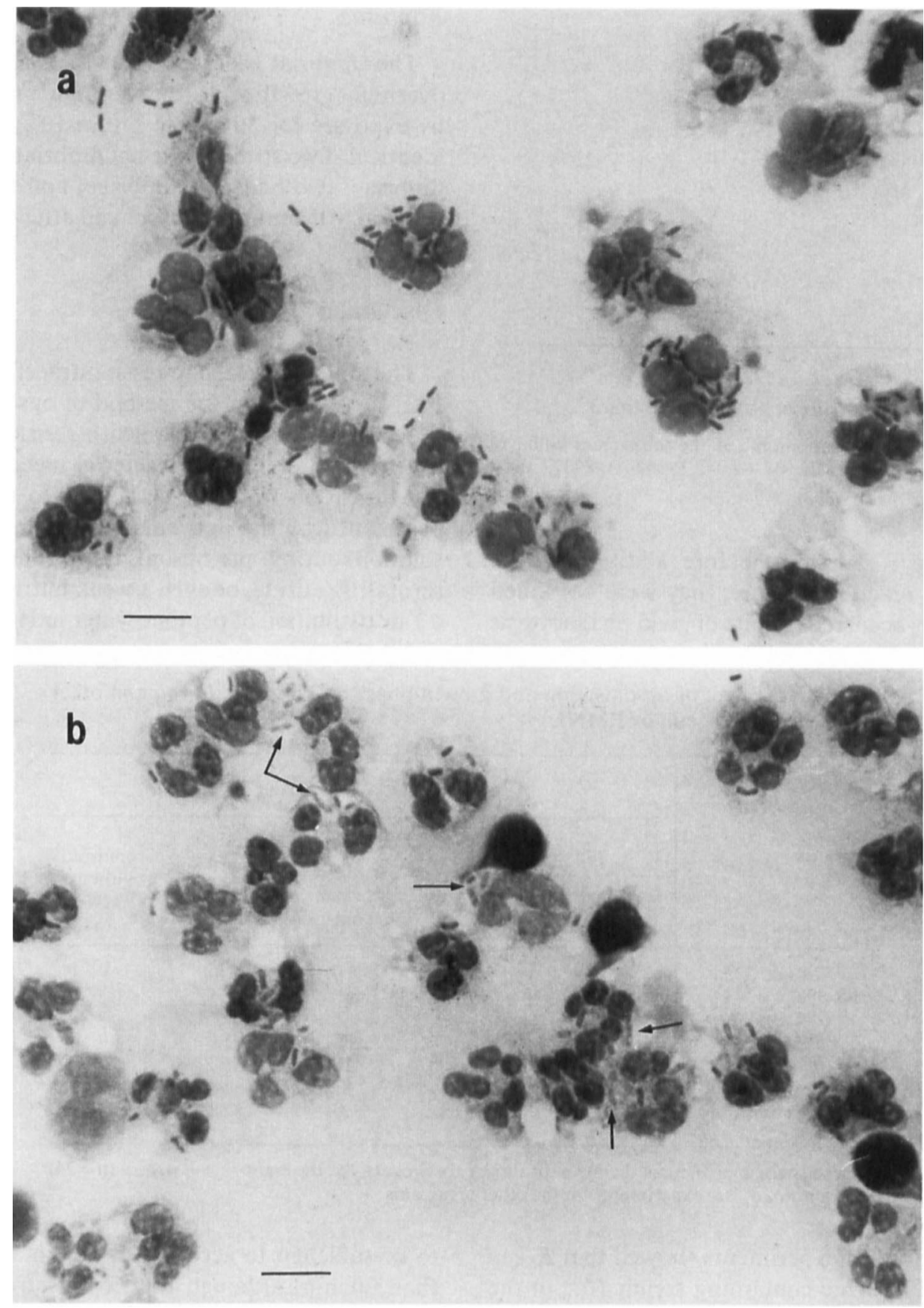

Fig. 1. (a) The effect of pre-opsonisation-most organisms are well stained and appear healthy; there was no evidence of killing as judged by viable counts. (b) The effect of opsonisation in the PMNL-serum reaction mixture-most intracellular organisms have undergone degenerative changes and many in the phagolysosomes appear poorly stained; arrows mark some examples; viable counts showed $82 \%$ killing. Bar $=10 \mu \mathrm{m}$.

$30 \mathrm{~min}$, regardless of the medium used. Thus, HBSS with serum $10 \%$ and pooled urine alone or with serum $10 \%$, did not increase the bacterial count over a 30 min period.

\section{Other gram-negative bacteria}

Pre-opsonised and unopsonised strains of $A$. lwoffi, Ent. cloacae and $P$. aeruginosa in the exponential or stationary phase were uniformly sensitive to intracellular killing by PMNL (table III). Stained smears of each preparation confirmed that phagocytosis had taken place.

\section{Experiments in urine}

Five strains of E. coli $(323,398,401,441$ and $\mathrm{Bi}-$ 8337) which had been killed by PMNL in HBSS were examined for killing by PMNL in sterile pooled human urine. When these strains, grown overnight in broth and resuspended in urine, were opsonised in the reaction mixture containing urine, serum $10 \%$ and PMNL, killing was observed (table IV). This was accompanied by very good phagocytosis (mean $98 \%$ ) with an average bacterial uptake of 8.1 organisms/ PMNL. However, when these strains were opsonised for 30 min in urine containing serum $10 \%$ or incubated 


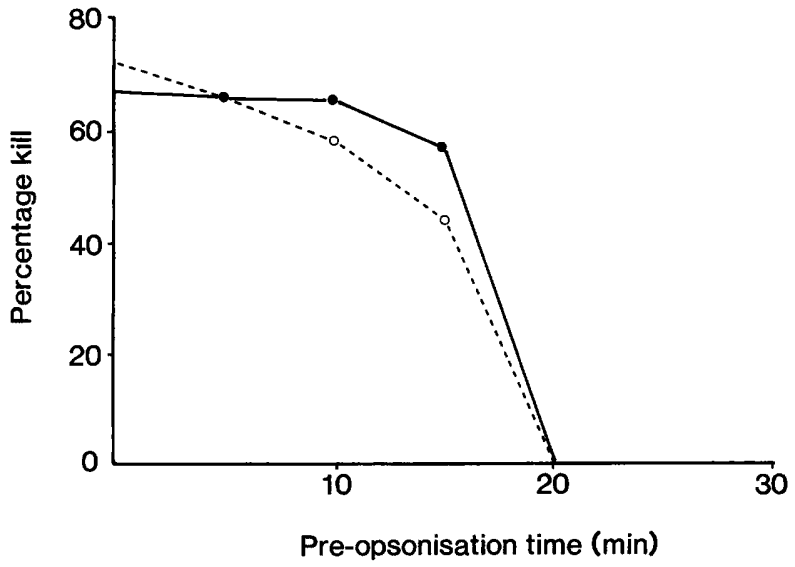

Fig. 2. Effect of pre-opsonisation time on the subsequent killing of $E$. coli by PMNL (mean values); -,$E$. coli $\mathrm{Bi}-8337, \mathrm{n}=3$; ,-- E. coli $441, \mathrm{n}=2$.

in urine alone for $30 \mathrm{~min}$, before addition to the PMNL-serum reaction mixture, they were not killed (table IV). This occurred in spite of good phagocytosis

\section{Fimbriae}

The fimbrial status of $10 \mathrm{E}$. coli strains after overnight growth and after overnight growth followed by exposure for $30 \mathrm{~min}$ to serum $10 \%$, proved to be identical. Two strains were not fimbriate, two had MS fimbriae, two had MR fimbriae, and four had both MS and MR fimbriae, before and after opsonisation.

\section{Discussion}

The ability of $E$. coli to resist intracellular killing by PMNL depends on the method of opsonisation. Our observations can be explained if resistance to killing is a result of changes in bacterial metabolism during the transition from the stationary to the lag phase, occasioned by the nutrients present in a $10 \%$ serum solution during pre-opsonisation. The presence of serum $10 \%$, urine, or even a weak nutrient solution of a 1 in 10 dilution of peptone water in HBSS, appeared

Table III. Effect of opsonisation and growth phase on killing of $E$. coli and other gram-negative bacilli by PMNL

\begin{tabular}{|c|c|c|c|c|c|}
\hline \multirow{3}{*}{ Strain } & \multicolumn{5}{|c|}{ Percentage killing of bacteria } \\
\hline & \multicolumn{2}{|c|}{ pre-opsonised } & \multicolumn{2}{|c|}{$\begin{array}{l}\text { opsonised in } \\
\text { reaction mixture }\end{array}$} & \multirow{2}{*}{$\begin{array}{l}\text { control } \\
\text { without } \\
\text { PMNL }\end{array}$} \\
\hline & exponential & stationary & exponential & stationary & \\
\hline $\begin{array}{l}\text { E. coli strain } 323, \\
395,398,401,441 \\
519,227, \text { Bi-8337 }\end{array}$ & $0^{*}$ & $\mathbf{0}$ & $\mathbf{0}$ & 76 & 0 \\
\hline E. coli strain 244 & 94 & 81 & 77 & 91 & 0 \\
\hline A. lwoffi & 92 & 81 & 88 & 90 & 0 \\
\hline Ent. cloacae & 93 & 92 & 88 & 94 & 0 \\
\hline P. aeruginosa & 97 & 92 & 95 & 88 & 0 \\
\hline
\end{tabular}

*Results are expressed as the mean of three experiments, for the eight $E$. coli strains $(n=24)$ and a mean of two experiments for the other organisms.

(mean $99 \%$ ). Control experiments showed that E. coli was not killed in urine containing serum $10 \%$ in the absence of PMNL.

Table IV. Effect of pre-opsonisation and pre-incubation in urine on killing of E. coli by PMNL

\begin{tabular}{l|cccc}
\hline & \multicolumn{4}{|c}{ Percentage killing of E. coli } \\
\cline { 3 - 5 } $\begin{array}{c}\text { Strain } \\
\text { no. }\end{array}$ & $\begin{array}{c}\text { pre- } \\
\text { opsonsed }\end{array}$ & $\begin{array}{c}\text { pre- } \\
\text { incubated }\end{array}$ & $\begin{array}{c}\text { opsonised } \\
\text { in reaction } \\
\text { mixture }\end{array}$ & $\begin{array}{c}\text { control } \\
\text { without } \\
\text { PMNL }\end{array}$ \\
\hline 323 & $0^{*}$ & 0 & 39 SD 9 & 0 \\
398 & 0 & 0 & 52 SD 8 & 0 \\
401 & 0 & 0 & 42 & 0 \\
441 & 0 & 0 & 61 & 0 \\
Bi-8337 & 0 & 0 & 64 & 0 \\
\hline
\end{tabular}

* Results are expressed as the mean (SD) of four experiments for strains 323 and 398 and mean of two experiments for the other strains. to be sufficient to accomplish this in a period of less than $30 \mathrm{~min}$, although the $E$. coli strains were well phagocytosed. They were also resistant to killing by PMNL in their exponential phase but reverted to being sensitive later in the stationary phase.

The development of resistance was not associated with bacterial division, because there was no increase in the viable counts of any of the strains of stationary phase $E$. coli during the $30-\mathrm{min}$ pre-opsonisation period in any of the media. This is in keeping with the findings of others ${ }^{6}$ who showed that the mean lag phase of six strains of $E$. coli in shake culture in urine, which greatly favours their growth, was $53 \mathrm{~min}$ (range $27-83 \mathrm{~min}$ ).

The growth phase of $E$. coli can affect the ability of PMNL to kill these organisms. ${ }^{7}$ Mouse peritoneal PMNL effectively killed four strains of $E$. coli grown from 20-h cultures when opsonised together with PMNL in the reaction mixture. However, two of the strains became resistant when grown to their exponen- 
tial phase. It is interesting that $E$. coli in the exponential phase that remained sensitive to killing by PMNL, and those that developed resistance, were able to induce a PMNL respiratory burst, as detected by the chemiluminescent response. Similarly, it has been shown ${ }^{8}$ that exponential phase Listeria monocytogenes were more resistant to the extracellular products of PMNL that had been stimulated by phorbol myristate acetate than those in the stationary phase. This was attributed to the $2 \cdot 5$-fold higher catalase activity of the organisms during growth. However, it was not possible to demonstrate this difference with $E$. coli strains. $^{8}$

We found that resistance to killing by PMNL developed in eight of 11 strains of $E$. coli during the transition from the stationary phase to the lag phase. One strain remained sensitive and two strains resisted killing by PMNL despite changes in the opsonisation procedure or growth phase. For technical reasons we were only able to test serum-resistant strains, which make up about $22 \%$ of strains causing urinary tract infections. ${ }^{9}$ This resistance did not occur in the other gram-negative genera we tested. However, it should be noted that we tested only one strain from each genus.

The ability of peptone water diluted in HBSS to substitute for serum $10 \%$ in bringing about resistance to killing indicated that a serum factor was not involved, as we previously thought. ${ }^{10}$

Production of fimbriae by $E$. coli is known to vary with growth conditions and PMNL interactions with fimbriate $E$. coli cells can alter the bactericidal oxidative mechanism. ${ }^{11}$ However, our findings with a range of fimbriate and non-fimbriate $E$. coli strains,

\section{References}

1. Leijh PCJ, Van Furth R, Van Zwet TL. In vitro determination of phagocytosis and intracellular killing by polymorphonuclear and mononuclear phagocytes. In: Weir DM (ed) Handbook of experimental immunology, 4th edn, vol 2. Oxford, Blackwell Scientific Publications. 1986: 46.146.21.

2. Eggleton P, Gargan R, Fisher D. Rapid method for the isolation of neutrophils in high yield without the use of dextran or density gradient polymers. J Immunol Methods 1989; 121 : 105-113.

3. Babior BM, Cohen HJ. Measurement of neutrophil function: phagocytosis, degranulation, the respiratory burst and bacterial killing. In: Cline MJ (ed) Methods in haematology, vol 3. New York, Churchill Livingstone. 1981 : 1-38.

4. Gargan RA, Brumfitt W, Hamilton-Miller JMT. Failure of water to lyse polymorphonuclear neutrophils completely: role of $\mathrm{pH}$ and implications for assessment of bacterial killing. J Immunol Methods 1989; 124: 289-291.

5. Old DC. Haemagglutination methods in the study of Escherichia coli. In: Sussman M (ed) The virulence of Escherichia coli, reviews and methods (Special publication of the Society for General Microbiology, 13). London, Academic Press. 1985: 287-313.

6. Anderson JD, Eftekhar F, Aird MY, Hammond J. Role of bacterial growth rates in the epidemiology and pathogen- show that no one fimbrial type was associated with the emergence of resistance to killing by PMNL.

Our findings demonstrate that phagocytosis of $E$. coli was not impaired in pooled urine with an osmolality of $504 \mathrm{mOsm} / \mathrm{kg}, \mathrm{pH} 6.9$, and that killing of $E$. coli by PMNL in urine, although reduced in comparison to HBSS, could nevertheless take place adequately. In contrast, $E$. coli strains became completely resistant to killing by PMNL after a $30-\mathrm{min}$ pre-incubation period in urine, with or without serum, and this is consistent with the availability of nutrients. Since opsonisation can take place in urine $e^{12}$ and, assuming that opsonisation, or prior incubation of the $E$. coli, occurs for $30 \mathrm{~min}$ or longer before phagocytosis can take place, PMNL may be unable to kill $E$. coli in vivo. It has been shown that urine can become inhibitory to phagocytosis because of a decrease in $\mathrm{pH}$ or an increase in osmolality or urea concentration, among other factors. ${ }^{13}$ Thus, it is possible that the urine environment may slow down phagocytosis for long enough to allow $E$. coli to develop resistance to killing by PMNL.

We conclude that killing of $E$. coli by PMNL is crucially dependent on how the $E$. coli are opsonised and their growth phase. Phagocytosis can be demonstrated regularly but most strains of $E$. coli investigated are not killed intracellularly if they have been exposed to nutrients for a period of $30 \mathrm{~min}$, or are in the exponential growth phase. Urine contains sufficient nutrients to render $E$. coli resistant to killing. Further work is necessary to demonstrate the extent to which urinary tract infections are caused by strains of $E$. coli capable of developing this rapid resistance to killing by PMNL in urine. esis of urinary infections in women. J Clin Microbiol 1979; 10: 766-771.

7. Iwahi T, Imada A. Interaction of Escherichia coli with polymorphonuclear leukocytes in pathogenesis of urinary tract infection in mice. Infect Immun 1988; 56: 947-953.

8. Bortolussi R, Vandenbroucke-Grauls CM, Van Asbeck BS, Verhoef J. Relationship of bacterial growth phase to killing of Listeria monocytogenes by oxidative agents generated by neutrophils and enzyme systems. Infect Immun 1987; 55: 3197-3203.

9. Taylor PW. Sensitivity of some smooth strains of Escherichia coli to the bactericidal action of normal human serum. $J$ Clin Pathol 1974; 27 : 626-629.

10. Gargan RA, Ahmed P, Hamilton-Miller JMT, Brumfitt W. Prevention of neutrophil killing of Escherichia coli by preopsonisation. J Med Microbiol 1990; 31 : x (abstract).

11. Björkstén B, Wadström $T$. Interaction of Escherichia coli with different fimbriae and polymorphonuclear leukocytes. Infect Immun 1982; 38: 298-305.

12. Suzuki Y, Fukushi Y, Orikasa S, Kumagai K. Opsonic effect of normal and infected human urine on phagocytosis of Escherichia coli and yeasts by neutrophils. JUrol $1982 ; 127$ : 356-360.

13. Chernew I, Braude AI. Depression of phagocytosis by solutes in concentrations found in the kidney and urine. $J$ Clin Invest 1962; 41: 1945-1953. 